\title{
EDUCAÇÃO AMBIENTAL NO ENSINO FORMAL PARA O CORRETO MANEJO DE RESÍDUOS
}

\author{
Nilva Lúcia Rech Stedile ${ }^{1}$ \\ Ana Maria Paim Camardelo² \\ Fernanda Meire Cioato $^{3}$
}

Resumo: A segregação correta dos resíduos é fundamental para a redução dos impactos destes sobre o meio ambiente. O objetivo do estudo foi analisar a efetividade de um programa de Educação Ambiental no desenvolvimento de aprendizagens para o correto manejo de resíduos. Trata-se de uma pesquisa-ação desenvolvida em duas escolas públicas de ensino fundamental em Caxias do Sul. Os resultados mostraram que a gincana e as atividades específicas por série escolar favoreceram a incorporação de ideias, a problematização de situações, a construção e ressignificação de conceitos e a compreensão dos desafios socioambientais no manejo dos resíduos. A Educação Ambiental é um potente recurso de aprendizagem, facilitando a construção de conhecimento significativo.

Palavras-chave: Educação Ambiental; Saúde Ambiental; Resíduos Sólidos; Catadores.

Abstract: The correct segregation of waste is fundamental to reduce its impacts on the environment. The objective was to analyze the effectiveness of an environmental education program in the development of learning for the correct management. It is an action research developed in two public elementary schools in Caxias do Sul. The results showed that the gymkhana and the specific activities by school grade favored the incorporation of ideas, the problematization of situations, the construction and re-signification of concepts and the understanding of socio-environmental challenges in waste management. Environmental education is a powerful learning resource, facilitating the construction of significant knowledge.

Keywords: Environmental Education; Environmental Health; Solid Waste; Solid Waste Segregators. 


\section{Introdução}

No decorrer das últimas décadas foi se construindo o que no momento se estabeleceu como um grande desafio para o modelo de desenvolvimento capitalista vigente que é a conciliação entre o padrão de consumo e a qualidade ambiental da vida na sociedade. $O$ efeito da geração exacerbada de resíduos, a inadequada segregação e o destino incorreto são inversamente proporcionais aos fatores condicionantes à sadia qualidade de vida e a sustentabilidade (BRASIL,1999), especialmente se considerado que grande parte das doenças que acometem a população brasileira tem como força motriz a qualidade ambiental. Conforme a OMS, estima-se que $24 \%$ da carga global de doenças e mais de um terço das doenças que acometem o público infantil, devam-se a fatores ambientais modificáveis (WHO, 2016). Devido a isso, os profissionais de saúde precisam incluir no rol de suas competências a Educação Ambiental.

Um dos problemas a serem enfrentados pela sociedade é o manejo e o destino ambientalmente correto dos resíduos, entre esses os gerados nos domicílios, cuja geração aumenta a cada ano. Estudiosos ressaltam que os resíduos domiciliares têm sido identificados como algo descartável, como sujeira e sem utilidade (VIEIRA, 2012). Essa percepção possivelmente é um dos fatores que influenciam no fato dos cidadãos não realizarem a correta segregação. O mesmo ocorre com resíduos de serviços de saúde (CUNHA, 2017), o que acaba comprometendo o ciclo produtivo e a saúde dos catadores de resíduos, evidenciando o não entendimento da relação entre resíduos e saúde (HAMMES; STEDILE; CAMARDELO, 2016).

Os catadores encontram-se expostos a diversos riscos físicos, químicos e biológicos em suas atividades. Conforme Hammes, Stedile e Camardelo (2016), as condições de trabalho dos catadores são permeadas por diversas formas de precariedade laboral: contato direto com os resíduos; trabalho árduo; baixa renda; falta de equipamentos; precária infraestrutura dos ambientes de trabalho, presença de resíduos perigosos junto à recicláveis. Apesar das condições de trabalho serem precárias e inadequadas, essas não são destacadas como um dos maiores motivos de insatisfação no trabalho. Esses trabalhadores ressaltam o preconceito, a discriminação e a incompreensão pelo tipo de trabalho como os principais aspectos que dificultam a sua realização (HAMMES; STEDILE; CAMARDELO, 2016; COELHO et al., 2017).

Nesse contexto, o sistema educativo é desafiado a trabalhar os temas ambientais em diferentes esferas para a compreensão da interface entre comportamento antrópico, consequências ambientais e efeitos na saúde. A Educação Ambiental (EA) implica na construção de conhecimentos, habilidades, atitudes concernentes às competências direcionadas para a conservação do meio ambiente, em todos os níveis do processo educativo (BRASIL, 1999). Essa percepção da necessidade de mudanças atitudinais 
frente à realidade ambiental desenvolve-se, entre outras situações, quando o ensino formal aborda a EA transitando entre as diferentes disciplinas.

As Diretrizes Curriculares Nacionais (DCN) para a EA objetivam, entre outros, a construção da responsabilidade cidadã, na reciprocidade das relações dos seres humanos entre si e com a natureza (BRASIL, 2012). Tanto na Política Nacional de EA quanto as DCN consta que a EA tem que atingir capilaridade, ou seja, os atores devem imprimir ao desenvolvimento individual um caráter social em sua relação com o meio ambiente, transformando-se em agentes ambientais, visando potencializar a prática de promover ética e cidadania ambiental (BRASIL, 1999; BRASIL, 2012)

No que tange ao desenvolvimento da compreensão integrada do meio ambiente de forma interdisciplinar, Pelicioni (2015) aponta que a abordagem curricular nas áreas de conhecimento aparece ainda de forma compartimentada, o que dificulta o aprofundamento do pensamento críticoreflexivo dos estudantes de forma integral e transversal acerca da temática.

Nesse cenário, estratégias de EA fazem-se necessárias por ser esse um processo coletivo, com propósito de desenvolver potencialidades essenciais na relação cidadão e meio ambiente, para construção de valores socioambientais, com o objetivo final de melhorar a qualidade de vida e ambiental da coletividade e garantir sua sustentabilidade (PELICIONI, 2015). Atividades eficazes que tornem evidente a inter-relação saúde e ambiente propõem capacitar indivíduos para o compromisso com o meio ambiente, em um primeiro momento, pelo entendimento do processo de desequilíbrio ambiental para que posteriormente sejam executadas estratégias de educação na saúde (BESERRA, 2010), aumentando a probabilidade de ocorrer aprendizagem significativa.

Importante destacar que a EA não pode ser desenvolvida de qualquer forma. Evidências apontadas por Bomfim et al. (2013, p. 27), ao analisarem a questão da transversalidade dos temas "saúde" e "ambiente" em projetos de cursos e documentos oficiais sobre educação mostram que:

[...] os textos, de maneira geral, são pouco atraentes; pouco práticos; apresentam dificuldades em dar pistas de ação; não mostram bem as diferentes interfaces com as diferentes áreas; não facilitam a visualização do sentido em que ocorre a trans e a interdisciplinaridade; apresentam-se em alguns momentos lacunares ou superficiais; e têm uma proposta de educação comportamentalista. Nesse limite, a educação serve mais à conformação do que à transformação da realidade; responsabiliza demasiadamente o indivíduo e isenta o Estado; promove uma cidadania passiva, que alcança a compreensão do direito, mas não a sua realização. 
Dessa forma, busca-se analisar a efetividade de um projeto de Educação Ambiental implementado em duas escolas de ensino fundamental no desenvolvimento de aprendizagens para o correto manejo de resíduos sólidos. A construção dos programas de Educação Ambiental envolveu toda a comunidade escolar (estudantes, professores, funcionários) e pais, no desenvolvimento das temáticas "manejo dos resíduos sólidos" e "papel do catador como agente ambiental", como forma de maximizar a probabilidade de desenvolvimento de comportamentos compatíveis com a proteção ambiental e à saúde pública.

\section{Métodos}

O percurso metodológico deste trabalho pode ser descrito, quanto ao objetivo, como pesquisa-ação, de natureza qualitativa, que inclui a elaboração e a aplicação de duas propostas pedagógicas executadas em duas escolas. A pesquisa-ação se caracteriza pelo envolvimento dos participantes de modo cooperativo na resolução de um problema coletivo (GIL, 2018). Conforme o mesmo autor, a análise qualitativa busca um diagnóstico para um problema específico em uma situação específica, com o objetivo de alcançar um resultado prático. No contexto desse estudo, houve o desenvolvimento de uma gincana (Escola A) e de atividades pedagógicas, como por exemplo atividades lúdicas e ensino com pesquisa (Escola B), para favorecer o desenvolvimento de conhecimento, habilidades e atitudes para o correto manejo dos resíduos e para o entendimento do papel e importância do catador como agente ambiental.

A gincana, desenvolvida na Escola $A$, é considerada uma técnica educativa que se utiliza da pedagogia ambiental com a estratégia grupal na tentativa de mediar a relação homem e natureza, consigo mesmo e com outros homens (LUZZI, 2012). Na Escola B foram desenvolvidas diferentes atividades lúdicas, oficinas e ensino com pesquisa por série escolar, para desenvolver a capacidade de estudar um problema em grupo, estimular a discussão e 0 debate, e aprofundar a discussão de um tema chegando a conclusões (MASSETO, 2012). Houve o cuidado de estabelecer uma relação com os conteúdos integrantes do currículo, definidas após reuniões com direção e professores, optando-se por metodologias de aprendizagem ativa, visto que os estudantes foram atores e protagonistas nos processos de aprendizagem.

Definiram-se coletiva e colaborativamente as estratégias de ensinoaprendizagem dirigidas a estudantes da educação infantil e do $1^{\circ}$ ao $5^{\circ}$ ano de duas escolas de ensino fundamental do município de Caxias do Sul. A escolha das escolas para a realização das propostas deu-se pelo fato dessas localizarem-se em dois bairros identificados como os de maior grau de mistura de resíduos pelo sistema de coleta seletiva do município (CODECA, 2017) e serem escolas da rede municipal de ensino. 
As atividades foram elaboradas e executadas no período de outubro de 2017 a novembro de 2018, como parte do projeto de pesquisa "Segregação de Resíduos Sólidos Urbanos em Caxias do Sul: Proposição e Implementação de um Projeto de Educação Ambiental", aprovado pelo Comitê de Ética em Pesquisa da Universidade de Caxias do Sul, sob número CAAE: 69990817.9.0000.5341, parecer ํㅜ 2.172.732. O processo foi desenvolvido por uma equipe interdisciplinar, a qual envolvia pesquisadores e acadêmicos das áreas da Enfermagem, Serviço Social, Psicologia, Sociologia e Direito. Para o desenvolvimento da EA a interdisciplinaridade foi considerada um conceito chave devido à complexidade das questões que envolvem 0 ambiente (BESERRA, 2010).

A dinâmica de elaboração do projeto que compôs as atividades desenvolvidas nas escolas A e B obedeceu a uma ordem cronológica. Para facilitar o entendimento do processo planejado, ele está representado por meio de etapas, as quais podem ser observadas no Quadro 1.

Quadro 1 - Planejamento da execução das atividades das escolas A e B

\begin{tabular}{|c|c|}
\hline Etapas & Dinâmica de desenvolvimento \\
\hline $\begin{array}{l}\text { Reunião com a } \\
\text { Codeca }\end{array}$ & $\begin{array}{l}\text { Definição juntamente com a Companhia de Desenvolvimento de Caxias do } \\
\text { Sul dos bairros a serem desenvolvidas as atividades de Educação } \\
\text { Ambiental. Esses foram selecionados devido ao maior grau de mistura dos } \\
\text { resíduos provenientes dos mesmos, levando em conta os dados de uma } \\
\text { caracterização dos resíduos sólidos da coleta municipal desenvolvida em } \\
\text { projeto anterior. }\end{array}$ \\
\hline $\begin{array}{l}\text { Mapeamento dos } \\
\text { bairros }\end{array}$ & $\begin{array}{l}\text { Os bairros foram mapeados e diagnosticados quanto à presença de } \\
\text { instituições comunitárias (escolas, unidade básica de saúde, igrejas e } \\
\text { clubes) com possibilidade de implementação do programa. Foram } \\
\text { selecionadas escolas para a execução das atividades, devido ser um } \\
\text { ambiente de aprendizagem, o público encontrar-se em um período de vida } \\
\text { no qual ocorre ampla construção de conhecimento e pelo fato das crianças } \\
\text { serem multiplicadoras natas. A escolha das escolas seguiu os critérios de } \\
\text { localização e ser da rede municipal de ensino. }\end{array}$ \\
\hline $\begin{array}{l}\text { Reunião com a } \\
\text { Secretaria Municipal } \\
\text { de Educação }\end{array}$ & $\begin{array}{l}\text { A Secretaria de Educação do Município foi contatada para a apresentação } \\
\text { da proposta, bem como para a definição das escolas e encaminhamento da } \\
\text { equipe de pesquisa às escolas selecionadas. }\end{array}$ \\
\hline $\begin{array}{l}\text { Elaboração das } \\
\text { atividades }\end{array}$ & $\begin{array}{l}\text { As propostas de atividades na forma de gincana e de tarefas didáticas por } \\
\text { série escolar foram elaboradas considerando-se estratégias de solução de } \\
\text { problemas e estudo de caso, pela exigência de um pensamento reflexivo a } \\
\text { partir de um problema; de oficinas, pela ênfase na construção, } \\
\text { reconstrução e aprofundamento de conhecimentos previamente adquiridos; } \\
\text { ensino com pesquisa, pela participação ativa dos estudantes e a } \\
\text { consideração dos conhecimentos prévios, com discussão do objeto e o } \\
\text { confronto com a realidade (ANASTASIOU e ALVES, 2015). }\end{array}$ \\
\hline $\begin{array}{l}\text { Contato com as } \\
\text { escolas e } \\
\text { apresentação do } \\
\text { Programa }\end{array}$ & $\begin{array}{l}\text { A apresentação da proposta para as escolas ocorreu na Escola A para a } \\
\text { direção e professores em um dia de reunião com todos os professores do } \\
\text { ensino fundamental I e na Escola B para a direção, que se responsabilizou } \\
\text { pela socialização e definição das atividades com os professores de cada } \\
\text { série. }\end{array}$ \\
\hline
\end{tabular}

Continua... 
...continuação.

\begin{tabular}{|l|l|}
\hline \multicolumn{1}{|c|}{ Etapas } & \multicolumn{1}{c|}{ Dinâmica de desenvolvimento } \\
\hline $\begin{array}{l}\text { Escolha das } \\
\text { atividades }\end{array}$ & $\begin{array}{l}\text { A escolha das atividades foi realizada em equipe: direção, professores e } \\
\text { pesquisadores, conforme o plano pedagógico das séries escolares, } \\
\text { facilidade de envolvimento com os estudantes e disponibilidade de tempo. }\end{array}$ \\
\hline $\begin{array}{l}\text { Planejamento e } \\
\text { cronograma }\end{array}$ & $\begin{array}{l}\text { O planejamento das atividades foi realizado coletivamente e desenvolvido } \\
\text { conforme cronograma específico para cada escola. }\end{array}$ \\
\hline $\begin{array}{l}\text { Desenvolvimento } \\
\text { das atividades }\end{array}$ & $\begin{array}{l}\text { Escola A - Professores e pesquisadores participaram durante todo o } \\
\text { processo de desenvolvimento das tarefas. } \\
\text { Escola B - Professores atuaram no desenvolvimento das atividades e os } \\
\text { pesquisadores na fase inicial e final do processo. }\end{array}$ \\
\hline $\begin{array}{l}\text { Avaliação das } \\
\text { atividades }\end{array}$ & $\begin{array}{l}\text { Realizada de forma processual, ao longo da realização de cada atividade e } \\
\text { mediante feedback dos participantes nas respectivas ações. Também foi } \\
\text { utilizado um questionário de avaliação de conhecimentos prévios e } \\
\text { conhecimentos construídos ao longo do processo. }\end{array}$ \\
\hline
\end{tabular}

Fonte: Elaborado pelas autoras.

$\mathrm{Na}$ Escola $\mathrm{A}$ as atividades foram desenvolvidas no período da manhã, em dias letivos e em um sábado, esse com participação dos pais. Participaram 268 estudantes do $1^{\circ}$ ao $5^{\circ}$ ano, organizados em dez equipes, com integrantes das diferentes turmas de maneira transversal, as quais foram identificadas com nomes das associações de reciclagem do Município. Participaram da dinâmica das atividades 10 professores, cada um responsável por uma equipe e cerca de 80 pais de alunos.

A dinâmica de desenvolvimento de cada tarefa que compôs a gincana obedeceu a seguinte ordem: boas-vindas e orientações quanto a tarefa a ser realizada; respostas aos questionamentos e dúvidas; apresentação de conceitos conforme as características das tarefas; execução das ações com auxílio dos professores responsáveis por cada equipe que também era acompanhada pelos pesquisadores. Posteriormente, houve a execução das atividades que eram pontuadas de acordo com a sua importância e relação com os temas: reciclagem; redução; reutilização de resíduos; preservação ambiental; e papel do catador. As tarefas foram realizadas em salas específicas (QG's) para cada equipe e as propostas que demandavam a integração de todas as equipes foram executadas na quadra de esportes da escola. Em cada QG, para o desenvolvimento das práticas, havia um pesquisador que explicava o objetivo e as atividades e um professor responsável pelo grupo.

As atividades realizadas na Escola $B$ foram organizadas e executadas conforme a série escolar, da educação infantil ao $5^{\text {o }}$ ano do ensino fundamental, e trabalhadas por turma, totalizando 378 estudantes envolvidos dos turnos da manhã e tarde. As atividades da temática ambiental e dos resíduos sólidos foram incorporadas e relacionadas ao conteúdo programático de cada série, assim os novos conceitos foram sendo introduzidos à medida que os estudantes também aprendiam conteúdos do plano curricular. A atividade 
com os pais foi desenvolvida em um sábado, com 41 participantes. Foram utilizadas as estratégias pedagógicas de solução de problemas, painel, fórum, oficinas e ensino com pesquisa. Segundo Anastasiou e Alves (2015) essas atividades envolvem integração, trabalho em grupo, mobilização em busca de soluções, levantamento de hipóteses, análise de dados, além da habilidade de desenvolver argumentos consistentes acerca das questões ambientais.

As atividades foram registradas por meio fotográfico, por gravação de vídeos e diários de bordo escritos pelos pesquisadores. Os dados foram organizados e analisados para entendimento do impacto das atividades no desenvolvimento das habilidades requeridas para o correto manejo dos resíduos. A análise das aprendizagens dos estudantes com base nas apresentações foi realizada seguindo a técnica de Myers (2008) para análise da conversação e da fala, que leva a compreensões mais claras, descobrindo o que eles tomaram como sentido relevante à temática do meio ambiente.

\section{Resultados e discussão}

Os resultados estão organizados em dois grupos, conforme as propostas pedagógicas trabalhadas nas escolas $A$ e $B$.

\section{a) Gincana}

Em cada dia programado da gincana foram desenvolvidas atividades com as equipes. No conjunto, possuíam como foco central a significação de conceitos sobre a segregação correta dos resíduos e seu efeito para o meio ambiente. A interação permanente entre os pesquisadores, os professores, os estudantes e os gestores escolares, bem como com os objetos de aprendizagem selecionados coletivamente para cada tarefa, contribuiu para a ressignificação de conceitos e para formação de agentes ambientais mirins. As atividades realizadas com as equipes estão apresentadas no Quadro 2.

Quadro 2 - Descrição das competências/aprendizagens e de cada atividade realizada,

\begin{tabular}{|c|l|l|l|}
\hline Etapa & \multicolumn{1}{|c|}{ Atividades } & \multicolumn{1}{c|}{$\begin{array}{c}\text { Competências/ } \\
\text { aprendizagem }\end{array}$} & \multicolumn{1}{c|}{ Descrição } \\
\hline \multirow{6}{*}{$1^{\text {a }}$} & $\begin{array}{l}\text { Explicação da } \\
\text { gincana }\end{array}$ & $\begin{array}{l}\text { Desenvolver curiosidade, } \\
\text { estimular a participação e } \\
\text { a aprendizagem em } \\
\text { relação ao tema }\end{array}$ & $\begin{array}{l}\text { Apresentação para os estudantes da } \\
\text { proposta, abordando: tema; } \\
\text { proposta; duração; formação das } \\
\text { equipes; sorteio do nome da equipe; } \\
\text { proposição da primeira tarefa da } \\
\text { gincana (criação do crachá e escolha } \\
\text { do líder da equipe) }\end{array}$ \\
\cline { 2 - 4 } & $\begin{array}{l}\text { Confecção dos } \\
\text { crachás }\end{array}$ & $\begin{array}{l}\text { Desenvolver o espírito de } \\
\text { equipe } \\
\text { Compreender na prática } \\
\text { o conceito de "reutilizar" }\end{array}$ & $\begin{array}{l}\text { Elaboração de um crachá da equipe } \\
\text { com 100\% de material reciclável. Os } \\
\text { quesitos avaliados foram: } \\
\text { identificação da equipe; presença da } \\
\text { identificação do membro da equipe; } \\
\text { criatividade; relação com o tema }\end{array}$ \\
\cline { 2 - 4 } & $\begin{array}{l}\text { Escolha dos } \\
\text { líderes }\end{array}$ & $\begin{array}{l}\text { Desenvolver espírito de } \\
\text { equipe }\end{array}$ & $\begin{array}{l}\text { Escolha do líder e vice-líder para } \\
\text { representar a equipe }\end{array}$ \\
\hline
\end{tabular}

Continua... 
...continuação.

\begin{tabular}{|c|c|c|c|}
\hline Etapa & Atividades & $\begin{array}{l}\text { Competências/ } \\
\text { aprendizagem }\end{array}$ & Descrição \\
\hline \multirow{4}{*}{$2^{\mathrm{a}}$} & $\begin{array}{l}\text { Grito de } \\
\text { guerra }\end{array}$ & $\begin{array}{l}\text { Desenvolver espírito de } \\
\text { equipe e compreender a } \\
\text { necessidade do trabalho } \\
\text { em equipe em relação à } \\
\text { problemática ambiental }\end{array}$ & $\begin{array}{l}\text { As equipes elaboraram um grito de guerra } \\
\text { com a temática ambiental. A criatividade de } \\
\text { cada equipe foi avaliada }\end{array}$ \\
\hline & $\begin{array}{l}\text { Criação da } \\
\text { mascote }\end{array}$ & $\begin{array}{l}\text { Entender o conceito de } \\
\text { "reutilizar" } \\
\text { Selecionar um } \\
\text { aspecto/elemento ou } \\
\text { objeto representativo da } \\
\text { temática ambiental }\end{array}$ & $\begin{array}{l}\text { Confecção da mascote da equipe com a } \\
\text { identificação de nome que represente o } \\
\text { grupo. Os materiais deviam ser } 100 \% \\
\text { recicláveis. Foram avaliados os quesitos: } \\
\text { utilização de materiais recicláveis; } \\
\text { criatividade; relação com a temática }\end{array}$ \\
\hline & $\begin{array}{l}\text { Roda de } \\
\text { conversa } \\
\text { sobre } \\
\text { segregação } \\
\text { dos } \\
\text { resíduos }\end{array}$ & $\begin{array}{l}\text { Compreender a } \\
\text { segregação correta dos } \\
\text { resíduos } \\
\text { Diferenciar os tipos de } \\
\text { resíduos } \\
\text { Classificar os tipos de } \\
\text { resíduos }\end{array}$ & $\begin{array}{l}\text { No quadro da sala foram desenhadas } \\
\text { quatro lixeiras representativas dos resíduos } \\
\text { "orgânicos", "recicláveis", "perigosos" e } \\
\text { "rejeito". Houve um bate-papo sobre quais } \\
\text { os tipos de resíduos de caráter domiciliar } \\
\text { que devem ser descartados de forma } \\
\text { adequada em cada uma }\end{array}$ \\
\hline & $\begin{array}{l}\text { Prática de } \\
\text { segregação } \\
\text { dos } \\
\text { resíduos }\end{array}$ & $\begin{array}{l}\text { Realizar a segregação } \\
\text { adequada dos resíduos }\end{array}$ & $\begin{array}{l}\text { Cada estudante recebeu um tipo de } \\
\text { resíduo escrito em um bilhete e fixaram nas } \\
\text { lixeiras adequadas, conforme a atividade } \\
\text { anterior, seguida da discussão final dos } \\
\text { resultados. }\end{array}$ \\
\hline \multirow{2}{*}{$3^{\mathrm{a}}$} & $\begin{array}{l}\text { Curta- } \\
\text { metragem e } \\
\text { vídeo }\end{array}$ & $\begin{array}{l}\text { Compreender os } \\
\text { conceitos: reduzir, } \\
\text { reciclar e reutilizar }\end{array}$ & $\begin{array}{l}\text { As equipes assistiram o curta-metragem } \\
\text { "Um plano para salvar o planeta" e o vídeo } \\
\text { "Man", no cinema da Universidade sobre a } \\
\text { relação entre ação antrópica, resíduos } \\
\text { sólidos e meio ambiente }\end{array}$ \\
\hline & $\begin{array}{l}\text { Conversa } \\
\text { com } \\
\text { catadores }\end{array}$ & $\begin{array}{l}\text { Conhecer a atividade } \\
\text { laboral dos catadores e } \\
\text { perceber a sua } \\
\text { importância como } \\
\text { agente ambiental }\end{array}$ & $\begin{array}{l}\text { Bate-papo com catadores de uma } \\
\text { associação de reciclagem do Município } \\
\text { sobre suas atividades laborais }\end{array}$ \\
\hline \multirow{4}{*}{$4^{\underline{a}}$} & $\begin{array}{l}\text { Oficina de } \\
\text { segregação } \\
\text { de resíduos }\end{array}$ & $\begin{array}{l}\text { Diferenciar os tipos de } \\
\text { resíduo } \\
\text { Classificar os resíduos } \\
\text { Realizar a segregação } \\
\text { adequada dos resíduos }\end{array}$ & $\begin{array}{l}\text { Caracterização de resíduos recicláveis } \\
\text { coletados no bairro no dia da atividade e } \\
\text { exemplificação do destino correto de } \\
\text { demais tipos de resíduos domiciliares para } \\
\text { estudantes e seus familiares }\end{array}$ \\
\hline & $\begin{array}{l}\text { Oficina de } \\
\text { brinquedos }\end{array}$ & $\begin{array}{l}\text { Entender o conceito de } \\
\text { "reutilizar" }\end{array}$ & $\begin{array}{l}\text { Confecção de brinquedos a partir de } \\
\text { resíduos recicláveis }\end{array}$ \\
\hline & $\begin{array}{l}\text { Oficina de } \\
\text { elaboração } \\
\text { de vídeo } \\
\text { para os } \\
\text { catadores }\end{array}$ & $\begin{array}{l}\text { Compreender a } \\
\text { importância do trabalho } \\
\text { do catador para o meio } \\
\text { ambiente }\end{array}$ & $\begin{array}{l}\text { Elaboração de vídeo por pais e estudantes } \\
\text { sobre o papel do catador como um agente } \\
\text { ambiental }\end{array}$ \\
\hline & $\begin{array}{l}\text { Trilha } \\
\text { ecológica } \\
\text { sobre os } \\
\text { resíduos }\end{array}$ & $\begin{array}{l}\text { Compreender o } \\
\text { processo de reciclagem } \\
\text { dos resíduos e a } \\
\text { logística reversa }\end{array}$ & $\begin{array}{l}\text { A partir de uma trilha, os estudantes tinham } \\
\text { que responder perguntas acerca da } \\
\text { temática dos resíduos sólidos. Um dado } \\
\text { indicava quantas casas os jogadores } \\
\text { poderiam avançar a medida dos acertos }\end{array}$ \\
\hline
\end{tabular}


...continuação.

\begin{tabular}{|c|l|l|l|}
\hline Etapa & Atividades & \multicolumn{1}{c|}{$\begin{array}{c}\text { Competências/ } \\
\text { aprendizagem }\end{array}$} & \multicolumn{1}{c|}{ Descrição } \\
\hline \multirow{2}{*}{$5^{\underline{a}}$} & $\begin{array}{l}\text { Construção da } \\
\text { fantasia }\end{array}$ & $\begin{array}{l}\text { Apreender o conceito de } \\
\text { "reutilizar" }\end{array}$ & $\begin{array}{l}\text { As equipes criaram uma fantasia com } \\
100 \% \text { material reciclável para um } \\
\text { desfile. Foram avaliadas de acordo com } \\
\text { a criatividade e relação com o tema }\end{array}$ \\
\cline { 2 - 5 } & Desfile & $\begin{array}{l}\text { Socializar o } \\
\text { entendimento dos } \\
\text { conceitos por meio da } \\
\text { roupa idealizada }\end{array}$ & $\begin{array}{l}\text { Desfile para integração das equipes e } \\
\text { avaliação, por uma comissão, do grito } \\
\text { de guerra e das fantasias, com os } \\
\text { critérios: utilização 100\% materiais } \\
\text { recicláveis; estética; criatividade }\end{array}$ \\
\hline \multirow{2}{*}{ a } & $\begin{array}{l}\text { Divulgação dos } \\
\text { vencedores }\end{array}$ & $\begin{array}{l}\text { Promover a integração } \\
\text { das equipes }\end{array}$ & $\begin{array}{l}\text { Entrega das medalhas de primeiro, } \\
\text { segundo e terceiro lugar conforme as } \\
\text { pontuações das tarefas e de medalhas } \\
\text { de participação para todos os } \\
\text { estudantes, reconhecendo-os como } \\
\text { agentes ambientais mirins }\end{array}$ \\
\hline $7^{\underline{a}}$ & Teatro & $\begin{array}{l}\text { Compreender a } \\
\text { importância do trabalho } \\
\text { do catador para o meio } \\
\text { ambiente }\end{array}$ & $\begin{array}{l}\text { Todos os estudantes assistiram à peça } \\
\text { teatral "Não acaba na lata" realizada } \\
\text { pela Companhia "Tem Gente } \\
\text { Teatrando" no teatro da Universidade }\end{array}$ \\
\hline
\end{tabular}

Fonte: Elaborado pelas autoras com base no banco de dados da pesquisa

Foram diversificadas as estratégias de ensino-aprendizagem desenvolvidas pelas equipes na gincana, sendo, em sua maioria, tarefas que exigiam a participação em conjunto e o envolvimento dos estudantes, com destaque para as oficinas. A dinâmica dessa técnica de ensinagem é mais potente no desenvolvimento de conceitos do que a simples transmissão de informações (LUZZI, 2012; MASSETO, 2012; ANASTASIOU; ALVES, 2015; PELICIONI, 2015), uma vez que uma oficina se caracteriza como uma estratégia pedagógica "em que o espaço de construção e reconstrução do conhecimento são as principais ênfases. É lugar de pensar, descobrir, reinventar, criar e recriar, favorecido pela forma horizontal na qual a relação humana se dá" (ANASTASIOU; ALVES, 2015, p. 103).

Diferentes aprendizagens foram desenvolvidas, tais como: trabalhar em equipe; ampliar a compreensão sobre os problemas ambientais da atualidade; entender o papel de cada um na redução, reciclagem e reutilização dos resíduos; ressignificar os conceitos de reduzir, reutilizar, segregar, resíduo perigoso e rejeito. Duas competências foram fundamentais: manejar adequadamente os resíduos (o que exigiu habilidades para diferenciar, segregar e classificar adequadamente os mesmos) e compreender o papel do catador e a sua importância na proteção do meio ambiente.

Percebeu-se que as atividades realizadas que possuíam como proposta a construção de um objeto, como a confecção da mascote e da fantasia, houve maior envolvimento e interação entre os membros das equipes, possivelmente motivados também pela obtenção dos pontos correspondentes às tarefas. Em conjunto discutiam as possibilidades de realizar a tarefa 
proposta, reconhecendo a relação entre sujeito e coletivo na atividade, que constrói a significação cultural dos objetos de conhecimento (LUZZI, 2012).

Acerca da tarefa de confecção de uma mascote, três equipes desenvolveram super-heróis para representá-las, as demais equipes construíram animais, máquinas e um ser humano. A ideia de personagens com superpoderes para simbolizar a relação com o meio ambiente permite supor que os estudantes possuem a percepção de que a problemática ambiental pode ser resolvida por ações de "super-heróis". Isso significa, de certa forma, transferir a responsabilidade pela redução da geração e, principalmente, pela segregação adequada a outros, sem a percepção clara da responsabilidade individual frente às questões ambientais. Com base nessa constatação, o papel individual e intransferível de cada indivíduo no enfrentamento da problemática dos resíduos foi reforçado nas diferentes atividades.

Houve uma diversidade de propostas de fantasias confeccionadas. As características das ideias, que associam o pensar na resolução dos problemas ambientais por meio de símbolos fictícios, também puderam ser percebidas a partir das fantasias. No entanto, nesse contexto, a presença de super-heróis pode representar também um sentimento de empoderamento da equipe para lidar com o manejo dos resíduos.

A tarefa da segregação dos resíduos realizada posteriormente à explicação dialogada sobre o manejo e o destino ambientalmente correto, por meio da estratégia de solução de problemas, permitiu aos estudantes classificar os resíduos corretamente nas lixeiras (orgânico, reciclável, perigoso e rejeito), em quase sua totalidade. Identificou-se que os estudantes possuíam conhecimento prévio sobre a segregação dos resíduos orgânicos e recicláveis e as suas simbologias. Os termos "resíduos perigosos" e "rejeito" foram conceitos novos introduzidos em uma relação direta entre informação, aprendizagem para mudança de conduta e transformação cultural.

Vale destacar o contato direto das crianças com os catadores pelo grau de participação dos estudantes. Esse foi um método ativo, construtivo, dialógico e interativo, de interesse sobre o descarte adequado dos resíduos e a sua atividade laboral. Os estudantes formularam perguntas como: "Você já ficou doente"? e "Vocês encontram muitos resíduos colocados errados?", e em exemplificações de situações familiares das quais os resíduos foram dispostos de maneira adequada no dispositivo, como o acondicionamento de cacos de vidro em uma embalagem rígida para a proteção do catador. Diante disso, pode ser considerada uma aprendizagem com real significado, à medida que os participantes puderam incluí-las na estrutura de seu conhecimento prévio (AUSUBEL, 1980).

A escolha pela realização de oficinas decorreu desse conceito de aprendizagem significativa. A oficina, por exigir a participação de todos os membros das equipes e o exercício de atividades práticas, permitiu o acesso a conhecimentos prévios e à ressignificação de conceitos. 
O conjunto das oficinas realizadas com estudantes, pais e familiares permitiu a aproximação da comunidade escolar à temática dos resíduos e o fortalecimento do papel de cada indivíduo, independente da faixa etária, no processo de manejo dos resíduos, o que inclui desde a geração até o destino final ambientalmente correto. Portanto, todo indivíduo é responsável pelo resíduo gerado em todo o seu ciclo de vida.

Os jogos lúdicos possibilitaram a participação, a interação e a tomada de decisões. O jogo foi estrategicamente elaborado. Esse define tanto um objeto (o jogo em si), quanto a atividade de experimentá-lo (o ato de jogar). Segundo Vasconcellos, Carvalho e Araújo (2018), é uma atividade que traz satisfação, exige participação ativa do jogador, é experimentado socialmente, favorecendo a interação social e, por conseguinte, a aprendizagem. No caso dos resíduos, o jogo possibilitou a interação dos jogadores entre si e desses com os conceitos que estavam sendo construídos nas diferentes atividades da gincana.

Para Pelicioni (2015) é papel do educador desenvolver o potencial dos indivíduos por meio de situações que estimulem o seu crescimento. Observouse resultado satisfatório de aprendizagem pela qualidade, forma de participação e pelos acertos dos estudantes às questões relacionadas à temática. A preocupação com o descarte inadequado dos resíduos e o trabalho do catador foi verificada pelos questionamentos formulados pelas crianças em relação à dificuldade das atividades laborais desses profissionais.

Assim, a Educação Ambiental, por meio de uma gincana para formação de agentes ambientais mirins, pode ser considerada uma técnica educativa potente, uma vez que os estudantes se sentiram multiplicadores responsáveis pela proteção ambiental, o que pode ser percebido nas afirmações: "É a medalha mais importante que eu já tive, vou mostrar para toda a minha família", "Essa medalha eu vou guardar para sempre" e "Agora nós somos agentes ambientais mirins".

\section{b) Atividades pedagógicas por séries}

As atividades foram selecionadas e desenvolvidas ao longo de um trimestre da escola, em cada série escolar. Em um dia programado com a escola, as turmas socializaram os resultados das atividades desenvolvidas para as demais turmas e para os pesquisadores. A dinâmica desse dia deu-se por apresentação de resultados pelos estudantes, por série, e de uma oficina com grupos de alunos, na seguinte ordem: i) apresentação e socialização de conhecimentos apreendidos por cada turma; ii) oficina de segregação de resíduos sólidos desenvolvida pelos pesquisadores; iii) bate-papo sobre o papel do catador para o meio ambiente com base em uma apresentação sobre as condições das associações de reciclagem municipal; e iv) análise, debate e significados compreendidos do curta-metragem 'Um plano para salvar o planeta' (SOUSA, 2011) e do vídeo Man (CUTTS, 2012). 
Os resultados das atividades realizadas com as turmas estão apresentados no Quadro 3.

Quadro 3 - Descrição das competências adquiridas a partir das estratégias de aprendizagem desenvolvidas.

\begin{tabular}{|c|c|c|}
\hline Estratégias & Aprendizagens & $\begin{array}{c}\text { Habilidades } \\
\text { desenvolvidas }\end{array}$ \\
\hline $\begin{array}{l}\text {-Painel } \\
\text {-Oficina } 1\end{array}$ & $\begin{array}{l}\text { "A gente aprendeu as cores dos lixos, para separar e o } \\
\text { lixo orgânico e seletivo, e fizemos um monte de } \\
\text { brinquedos recicláveis" }\end{array}$ & $\begin{array}{l}\text {-Compreensão dos } \\
\text { tipos dos resíduos } \\
\text { conforme cor das } \\
\text { lixeiras } \\
\text {-Diferenciação de } \\
\text { resíduos orgânicos } € \\
\text { recicláveis } \\
\text {-Compreensão do } \\
\text { conceito de reutilizar }\end{array}$ \\
\hline $\begin{array}{l}\text { Ensino com } \\
\text { pesquisa }\end{array}$ & $\begin{array}{l}\text {-"Fizemos uma pesquisa de quanto tempo o lixo leva } \\
\text { para se decompor. E a gente trouxe algumas coisas de } \\
\text { casa para mostrar para vocês nesse cartaz" } \\
\text {-"O jornal demora oito anos, e o papelão demora de seis } \\
\text { a oito anos" } \\
\text {-"A lata de metal demora mais de cem anos para se } \\
\text { decompor, e a lata de alumínio de quatrocentos para } \\
\text { mais" } \\
\text {-"O plástico demora para se decompor na natureza } \\
\text { quatrocentos anos" }\end{array}$ & $\begin{array}{l}\text {-Entendimento do } \\
\text { tempo de } \\
\text { decomposição de } \\
\text { diferentes tipos de } \\
\text { resíduos } \\
\text {-Compreensão do } \\
\text { conceito de reutilizar }\end{array}$ \\
\hline $\begin{array}{l}\text { Solução de } \\
\text { problemas }\end{array}$ & $\begin{array}{l}\text {-"A profe deu um desafio que é produzir explicações } \\
\text { com materiais recicláveis" } \\
\text {-"Fazer multiplicações, por exemplo, } 2 \times 3 \text { é igual a } 6 \text {, } \\
\text { como } 2+2+2 \text { é } 6 \text {, e depois nos desafiou a fazer um jogo, } \\
\text { e um... algum brinquedo" }\end{array}$ & $\begin{array}{l}\text { Compreensão do } \\
\text { conceito de gerar } \\
\text { resíduo }\end{array}$ \\
\hline Fórum & 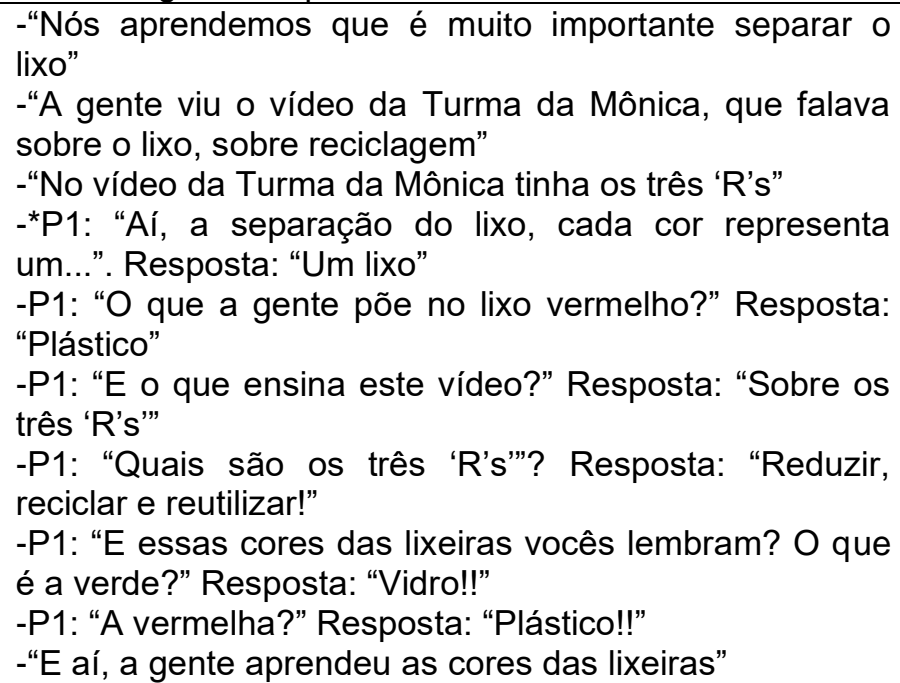 & $\begin{array}{l}\text {-Entendimento dos } \\
\text { conceitos de reduzir } \\
\text { reciclar e reutilizar } \\
\text {-Diferenciação das } \\
\text { lixeiras conforme a } \\
\text { sua cor }\end{array}$ \\
\hline
\end{tabular}

Continua... 
...continuação.

\begin{tabular}{|c|c|c|}
\hline Estratégias & Aprendizagens & $\begin{array}{l}\text { Habilidades } \\
\text { desenvolvidas }\end{array}$ \\
\hline $\begin{array}{l}\text {-Estudo de } \\
\text { caso } \\
\text {-Ensino } \\
\text { com } \\
\text { pesquisa }\end{array}$ & $\begin{array}{l}\text {-"Por que a maioria das pessoas, na verdade todo } \\
\text { mundo, acha que é importante separar o lixo, mas tem } \\
\text { quatro famílias que não separam?" } \\
\text {-"Bom, muita gente das famílias, que a gente fez a } \\
\text { pesquisa, respondeu que produzem na sua casa muito } \\
\text { mais lixo seletivo. Quando o correto seria lixo orgânico. } \\
\text { Por quê? O lixo seletivo, muitas vezes, quando as } \\
\text { pessoas não separam, ele polui o meio ambiente e o } \\
\text { lixo orgânico não, porque ele pode se transformar em } \\
\text { composto para as fazendas" } \\
\text {-"Algumas famílias disseram que o container de lixo tem } \\
\text { no bairro delas e } 34 \text { disseram que não tinha, que } \\
\text { passava o caminhão. [...] E também tem um problema, } \\
\text { que a prefeitura não botou um container em todos os } \\
\text { bairros, só os principais" } \\
\text {-"Eu acho muito importante que a gente separe o nosso } \\
\text { lixo, porque se a gente botar tudo junto vai poluir ainda } \\
\text { mais. E tem muita gente que polui o meio ambiente, as } \\
\text { praias também jogando lixo nos mares, rios, isso pode } \\
\text { matar alguns animais. Então eu acho muito importante a } \\
\text { gente separar o lixo, porque isso é muito bom para o } \\
\text { planeta" }\end{array}$ & $\begin{array}{l}\text {-Percepção da } \\
\text { importância de } \\
\text { segregar os resíduos } \\
\text {-Utilização dos } \\
\text { resíduos orgânicos } \\
\text { como fertilizantes } \\
\text { naturais para o solo } \\
\text {-Compreensão das } \\
\text { consequências da } \\
\text { segregação incorreta } \\
\text { para o ambiente } \\
\text {-Entendimento da } \\
\text { relação da separação } \\
\text { dos resíduos por } \\
\text { vivência realística }\end{array}$ \\
\hline Oficina 2 & $\begin{array}{l}\text {-"A gente fez um rolo de papel higiênico, que a gente fez } \\
\text { um porta-lápis. Que a gente fez de bichinho [...]" } \\
\text {-"Eu, aqui no colégio, eu tinha uma cordinha, daí eu } \\
\text { tinha trazido um potinho de iogurte, aí eu furei em casa } \\
\text { e eu botei a cordinha. E minha mãe já tinha feito para } \\
\text { mim ver (telefone), e eu fiz um igual" } \\
\text {-"A gente fez com pote de iogurte, com tampinha e com } \\
\text { canudinho e com umas outras coisas (chocalho)" } \\
\text {-"Lixo de plástico é no amarelo e o verde é de casca de } \\
\text { fruta" }\end{array}$ & $\begin{array}{l}\text {-Compreensão do } \\
\text { conceito de reutilizar } \\
\text {-Conhecimento da } \\
\text { tipologia dos resíduos } \\
\text { conforme cor das } \\
\text { lixeiras }\end{array}$ \\
\hline $\begin{array}{l}\text {-Painel } \\
\text {-Oficina }\end{array}$ & $\begin{array}{l}\text {-"É, a gente, a prof. recortou lixo para botar uns no lixo } \\
\text { amarelo e outros no verde". } \\
\text {-**P2: "E quais que vão no lixo amarelo Pedro..." } \\
\text { Respostas: "Papel, garrafa", "As tampinhas" } \\
\text {-P2: "E no lixo verde, Pedro, o que vai?" Respostas: "A } \\
\text { casca de fruta", "Farelo de lápis, casca de maça e casca } \\
\text { de banana" } \\
\text {-P2: "Vocês fizeram um bicho". Com copinhos de...?" } \\
\text { Resposta: "logurte" } \\
\text {-P2: "E o que vocês estudaram sobre o Egito? O que } \\
\text { vocês usaram pra fazer a pirâmide?" Respostas: "A } \\
\text { gente usou caixa de leite", "E, e a gente usou caixa de } \\
\text { ovo, e, e", "E tampinha dos... dos...", "Das bebidas e } \\
\text { prendedor para as pernas" }\end{array}$ & $\begin{array}{l}\text {-Diferenciação dos } \\
\text { resíduos orgânicos e } \\
\text { recicláveis } \\
\text {-Diferenciação das } \\
\text { lixeiras conforme a } \\
\text { sua cor } \\
\text {-Compreensão do } \\
\text { conceito de reutilizar }\end{array}$ \\
\hline
\end{tabular}

Continua... 
...continuação.

\begin{tabular}{|c|c|c|}
\hline Estratégias & Aprendizagens & $\begin{array}{l}\text { Habilidades } \\
\text { desenvolvidas }\end{array}$ \\
\hline Painel & $\begin{array}{l}\text {-"Nós trabalhamos em aula sobre onde devemos } \\
\text { separar o lixo, na lixeira correta, e também aprendemos } \\
\text { a diferenciar lixo e resíduo" } \\
\text {-"Lixo: é o que foi jogado fora e não serve mais para } \\
\text { uso, por exemplo bateria" } \\
\text {-"Resíduo é o que foi descartado, mas pode ser usado } \\
\text { novamente para fabricação de novos produtos" } \\
\text {-"Devemos descartar o lixo na lixeira correta. Amarelo é } \\
\text { para metal, por exemplo: talheres, latinhas de } \\
\text { refrigerante e panelas" } \\
\text {-"A lixeira vermelha, plástico, é usada, como exemplo: } \\
\text { embalagem de produtos de limpeza, copos de plásticos, } \\
\text { copos de iogurte e sacos de embalagens" } \\
\text {-"A lixeira branca é para resíduos hospitalares e } \\
\text { seringas e agulhas" } \\
\text {-"A lixeira verde é para vidro. Exemplo: copos, cacos de } \\
\text { vidro, xícaras e taças de vidro" } \\
\text {-"A lixeira marrom é para restos de comida, por } \\
\text { exemplo, depois que você comeu a maçã para jogar o } \\
\text { cabinho fora, a casca da banana, casca da bergamota, } \\
\text { a casca da manga e muitas outras coisas" }\end{array}$ & $\begin{array}{l}\text {-Diferenciação dos } \\
\text { conceitos lixo e } \\
\text { resíduo } \\
\text {-Diferenciação dos } \\
\text { recipientes de } \\
\text { acondicionamento } \\
\text { (lixeira) conforme a } \\
\text { sua cor } \\
\text {-Conhecimento da } \\
\text { segregação adequada } \\
\text { dos resíduos }\end{array}$ \\
\hline
\end{tabular}

Fonte: Elaborado pelas autoras com base no banco de dados da pesquisa

Nota: ${ }^{*} \mathrm{P} 1$ - professora $1 ;{ }^{* *} \mathrm{P} 2$ - professora 2

Das atividades de aprendizagem resultaram diversos produtos como, porta-lápis (pinguim) e de personagens (caipira); animais (cobra e camelos); pirâmide egípcia, vários tipos de brinquedos; folders explicativos sobre o manejo e tipos de resíduos; mostra de resíduos perigosos eletrônicos; cartazes com exemplos de resíduos orgânicos e recicláveis; pesquisa bibliográfica sobre tempo de decomposição dos resíduos na natureza e pesquisa realizada com familiares sobre a reciclagem. Esses produtos construídos pelos estudantes a partir dos resíduos sólidos e sobre a reciclagem foram expostos na escola. Para entender a temática ambiental, as produções envolveram conteúdos de diferentes áreas, mostrando-se eficaz o trabalho com os resíduos sólidos de forma interdisciplinar e interprofissional.

Percebeu-se que as estratégias de "estudo de caso" e "ensino com pesquisa", foram as que possibilitaram maior compreensão dos estudantes na relação entre o tema dos resíduos e a prática de reciclagem no cotidiano. Essas técnicas de ensinagem, por exigirem uma dinâmica de mobilização dos indivíduos e reunirem a teoria com a prática, possibilitaram que os estudantes entendessem de maneira mais significativa essa problemática e o papel de cada um na sua solução. Isso pôde ser percebido pelo posicionamento crítico das crianças frente à realidade em relação aos resíduos (ANASTASIOU; ALVES, 2015). 
Quanto aos folders elaborados pelos estudantes foram diversas as ideias apresentadas, como a separação adequada dos resíduos, o tempo de decomposição dos materiais no ambiente, a importância da reciclagem para o meio ambiente e a relação entre resíduo, poluição e desastres ambientais. Como esses apresentaram perfis com diferentes informações, optou-se por separar palavras-chave ao longo dos textos dos folders explicativos, por meio do Programa WordClouds, a fim de se obter uma demonstração ilustrativa das principais palavras utilizadas nessa atividade, resultando o que é apresentado na Figura 1.

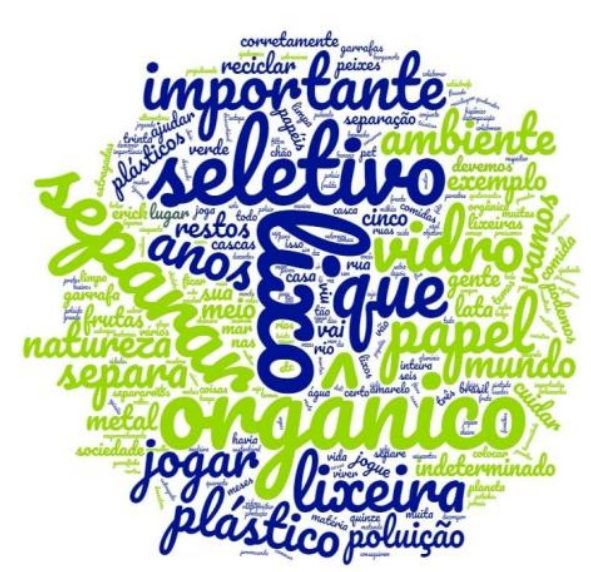

Figura 1: Principais palavras utilizadas pelos estudantes na elaboração dos folders Fonte: Elaborado pelas autoras com base nos folders

Conforme a ilustração, os termos mais utilizados foram: lixo; orgânico; seletivo; separar; importante; jogar; lixeira; anos; papel; vidro; plástico; ambiente; natureza; poluição; e mundo. Esse conjunto de palavras aponta para duas grandes habilidades fundamentais para mudança de comportamento frente aos resíduos: a separação dos resíduos seletivos (reciclável) e a destinação correta, especialmente do orgânico. Como a questão da compostagem do resíduo orgânico também foi objeto de trabalho, há probabilidade de que os mesmos possam ter um destino mais adequado do que o aterro sanitário ou a sua mistura com os recicláveis, o que é bem comum nos bairros onde o programa de Educação Ambiental foi desenvolvido.

De maneira geral, as atividades favoreceram a construção dos conhecimentos, habilidades e atitudes acerca da separação adequada dos resíduos sólidos, da classificação dos resíduos quanto a sua tipologia, da diferenciação das lixeiras por coloração e dos conceitos "reduzir" e "reutilizar". Verificou-se que as técnicas de Educação Ambiental utilizadas contribuíram para a aprendizagem de maneira satisfatória pela participação e envolvimento dos alunos na apresentação, pelo domínio de conceitos e pela qualidade dos trabalhos realizados. 


\section{Considerações Finais}

A gincana, as atividades lúdicas e a pesquisa desenvolvida pelos estudantes proporcionaram oportunidades ímpares para que esses pudessem problematizar diferentes situações vividas, buscando a compreensão dos desafios socioambientais e a sua transformação. Dessa forma, pode-se dizer que as experiências foram capazes de favorecer a incorporação de ideias, a construção e a ressignificação de conceitos e a percepção sobre formas de agir mais saudáveis e sustentáveis, especialmente em relação aos resíduos sólidos.

Dentre as atividades selecionadas destacam-se o jogo, a oficina, o ensino com pesquisa e o estudo de caso, que se constituíram como tecnologias educativas potentes para o desenvolvimento de novas formas de atuar no manejo dos resíduos, bem como para o entendimento do papel do catador como agente ambiental. A interação com o catador mostrando sobre o seu trabalho, as condições em que é realizado e a forma como o resíduo chega até esse trabalhador foram consideradas fundamentais para a consolidação do papel de cada um na correta segregação dos resíduos.

As principais habilidades desenvolvidas dizem respeito a capacidade de classificar os resíduos, segregar adequadamente, reconhecer o papel do catador, diferenciar "lixo" de "resíduo"; reduzir a geração; propor formas de reuso e utilizar resíduos orgânicos para compostagem.

Conceitos como: resíduo, rejeito, perigoso, reutilização, redução, reciclagem, segregação, sustentabilidade, proteção ambiental e cidadania permearam todas as atividades desenvolvidas de forma a colaborar na consolidação de novos conhecimentos. Espera-se que os participantes se tornem multiplicadores, de tal forma que possam desempenhar o papel de agentes ambientais mirins, consolidando novas formas de relação com o ambiente.

Assim, a gincana e as atividades pedagógicas se constituíram, nessa experiência, como potentes recursos para aprendizagem e contribuíram para uma experiência ativa e participativa, facilitando a construção de conhecimento significativo em coletividade, na defesa do meio ambiente e da qualidade de vida.

\section{Agradecimentos}

Ao Conselho Nacional de Desenvolvimento Científico e Tecnológico (CNPq), pelo incentivo à pesquisa; aos bolsistas do Núcleo de Estudos e Pesquisas em Políticas Públicas e Sociais e do Mestrado e Doutorado em Direito Ambiental da Universidade de Caxias do Sul por suas contribuições para o desenvolvimento do Projeto. 


\section{Referências}

ANASTASIOU, L.G.C.; ALVES, L.P (Org.). Processos de Ensinagem na Universidade: pressupostos para as estratégias de trabalho em aula. 10. ed. Joinville, SC: Univille, 2015. p. 86-107.

AUSUBEL, D.P.; NOVAK, J.D.; HANESIAN, H. Psicologia Educacional. 2.ed. Rio de Janeiro, RJ: Editora Interamericana, 1980.

BESERRA, E.P. et al. Educação Ambiental e enfermagem: uma integração necessária. Rev Bras Enferm. Brasília, v. 63, n. 5, p. 848-52, 2010.

BRASIL. Lei 9.795, de 27 de abril de 1999. Dispõe sobre a Educação Ambiental, institui a Política Nacional de Educação Ambiental e dá outras providências. Brasília, DF: Presidência da República 1999. Disponível em: https://bit.ly/3dl18T6 . Acesso em: 07 out. 2019.

BRASIL. Resolução $\mathbf{N}^{\circ}$ 2, de 15 de junho de 2012. Estabelece as Diretrizes Curriculares Nacionais para a Educação Ambiental. Brasília, DP: Ministério da Educação, 2012. Disponível em: https://bit.ly/2WQQt1D . Acesso em: 07 out. 2019.

BOMFIM, A.M. et al. Parâmetros curriculares nacionais: uma revisita aos temas transversais meio ambiente e saúde. Trab. educ. saúde. Rio de Janeiro, v. 11, n. 1, p. 27-52, 2013.

CODECA. Companhia de Desenvolvimento de Caxias do Sul. Associações de Reciclagem. Caxias do Sul, 2017. Disponível em: http://www.codeca.com.br/servicos coletas associacoes de reciclagem.php Acesso em 15 set. 2020.

COELHO, A.P.F. et al. Satisfaction and dissatisfaction in the work of recyclable solid waste segregators: convergent-care research. Rev Bras Enferm. Brasília, v. 70, n. 2, p. 402-9, 2017.

COUTO, M.S.D.S., GUIMARÃES, C.S., PEREIRA, M.F. Contribuições de uma experiência pedagógica em Educação Ambiental. Revipea. São Paulo, v. 12, n. 1, p. 26-41, 2017.

CUNHA, G.H. et al. Insulin therapy waste produced in the households of people with diabetes monitored in Primary Care. Rev Bras Enferm. Brasília, v. 70, n. 3, p. 646-53, 2017.

CUTTS, S. Man. 2012. 1 vídeo (3 min e $36 \mathrm{seg}$ ). Publicado no canal Steve Cutts. Disponível em: https://bit.ly/2Ahwhy j. Acesso em: 15 out. 2018.

GIL, A. C. Métodos e técnicas de pesquisa social. São Paulo: Atlas, 2018.

HAMMES, M.; STEDILE, N.L.R.; CAMARDELO, A.M.P. Processo de trabalho dos catadores de resíduos sólidos: uma análise de variáveis em grupos de trabalhadores na Serra Gaúcha. In: CAMARDELO, A.M.P; STEDILE, N.L.R. (Org.). Catadores e Catadoras de Resíduos: prestadores de serviços fundamentais à conservação do meio ambiente. Caxias do Sul, RS: Educs; 2016. p. 87-110.

Revbea, São Paulo, v.16, № 1: 96-113, 2021. 
LUZZI, D. Educação e meio ambiente: uma relação intrínseca. 1. ed. Barueri, SC: Manole, 2012.

MASSETO, M. T. Competência pedagógica do professor universitário. 2. ed. São Paulo: Summus, 2012.

MYERS, G. Análise da conversação e da fala. In: BAUER, M.W.; GASKELL, G. Pesquisa qualitativa com texto, imagem e som: um manual prático. 7. ed. Petrópolis, RJ: Vozes, 2008. P. 271-92.

PELICIONI, M.C.F. Fundamentos da Educação Ambiental. In: PHILIPPI JÚNIOR, A.; ROMÉRO, M.A.; BRUNA, G.C. Curso de Gestão Ambiental. 2.ed. Barueri, SP: Manole; 2015. p. 469-491.

SOUSA, M. Um plano para salvar o planeta. 2011. 1 vídeo (25 min e $32 \mathrm{seg}$ ). Publicado no canal Turma da Mônica, Disponível em: <https://bit.ly/3cpBpi6>. Acesso em: 08 out. 2018.

VASCONCELLOS, M.S.; CARVALHO, F.G. de; ARAÚJO, I.S. o jogo como prática de saúde. Rio de Janeiro: Fiocruz, 2018.

VIEIRA, P.C.; SILVEIRA, J.L.G.C.; RODRIGUES, K.F. Percepção e hábitos relacionados ao lixo doméstico entre moradores da comunidade do Coripós, Blumenau, SC. Rev. de APS. Santa Catarina, v. 15, n. 1, p. 82-91, 2012.

WORLD HEALTH ORGANIZATION - WHO. Preventing disease through healthy environments: a global assessment of the burden of disease from environmental risks. Geneva, 2016. Disponível em: <http://bit.ly/2J9be2l>. Acesso em: 2 out. 2019. 